\title{
Perinatal Outcome in Gestational Diabetes Melitus Vs Normoglycemic Women
}

\author{
Slagjana Simeonova Krstevska ${ }^{1 *}$, Valentina Velkoska Nakova ${ }^{2}$, Igor Samardziskii ${ }^{1}$, Aleksandra \\ Atanasova Bosku ${ }^{1}$, Irena Todorovska ${ }^{1}$, Aneta Sima ${ }^{1}$, Vesna Livrinova ${ }^{1}$, Viktorija Jovanovska ${ }^{1}$ \\ and Daniel Milkovski ${ }^{1}$
}

${ }^{1}$ University Clinic for obstetrics and gynecology, Macedonia

${ }^{2}$ University Goce Delcev, Macedonia

*Corresponding author: Slagjana Simeonova Krstevska, University Clinic for obstetrics and gynecology, Macedonia

\section{ARTICLE INFO}

Received: 幽 February 21, 2020

Published: March 05, 2020

Citation: Slagjana Simeonova K, Valentina Velkoska N, Igor S, Aleksandra Atanasova B, Irena T, etal., Perinatal Outcome in Gestational Diabetes Melitus Vs Normoglycemic Women. Biomed J Sci \& Tech Res 26(2)-2020. BJSTR. MS.ID.004338.

Keywords: Gestational Diabetes Mellitus; Perinatal Outcome; Neonatal Outcome

Abbreviations: GDM: Gestational Diabetes Mellitus; CG: Control Group; RDS: Respiratory Distress Syndrome

\section{ABSTRACT}

Introduction: Gestational Diabetes Mellitus (GDM) is glucose intolerance diagnosed for the first time in pregnancy. It may lead to potentially serious short term and longterm complications for both mother and fetus or newborn.

Material and Methods: Prospective study was conducted at the University clinic for gynecology and obstetrics, Skopje for the period of one year. 100 pregnant women in the second trimester which performed oral glucose tolerance test (75g OGTT) were evaluated. The study included 50 women with GDM and control group of 50 women with negative OGTT at the same gestational age, parity and maternal age. Gestational weight gain, blood pressure and urine analysis for proteinuria were recorded monthly. Patients with GDM were more often followed according to the clinical protocol. Maternal and neonatal data was collected after birth from medical records during discharge from the clinic. The perinatal outcome of pregnant women with or without GDM was analysed.

Results: There was a significant difference in BMI between the women with GDM and normoglycemic women. Hypertensive disorders of pregnancy, preterm labour and delivery by caesarean section were significantly more often in GDM pregnancies vs control group. Respiratory distress, hypoglycemia, $\mathrm{pH}<25$, lower Apgar score in the first minute and admission in the neonatal intensive care unit was significantly more often in the neonates from mothers with GDM vs controls.

Conclusion: Many parameters of the perinatal outcome were significantly associated with GDM in our study. Adequate treatment can achieve better maternal and neonatal outcome.

\section{Introduction}

GDM is most often metabolic complication of pregnancy with incidence between 1 and 14\% depending of characteristics of the selected population and diagnostic criteria [1]. GDM has increased risk for perinatal morbidity and markedly increased risk for type 2 diabetes. Perinatal risk in GDM is connected to uncontrolled glucose levels and GDM treatment may result in reduction of complications $[2]$.

\section{Maternal Risk}

Independently of birth weight association of caesarean section deliveries in GDM is more than 35\% compared to $20 \%$ in general population. Diagnosis of GDM alone leads to easier decision for cesarean section delivery [3,4]. GDM increases the risk for premature spontaneous and induced labor. Beigelman et al. showed that prevalence of spontaneous preterm labor was $7 \%$ 
in nondiabetic, $10 \%$ in GDM up to $25 \%$ in pregestational diabetes [5]. Increased risk for hypertensive disorders of pregnancy in GDM is connected to mutual risk will develop preeclampsia and preeclampsia predispose these women to complications like prematurity and IUGR [3].

\section{Fetal and Neonatal Complications}

Abnormal fetal growth, chemical imbalance and respiratory distress may result in admission of the newborn in ICU [6]. Fetuses exposed to higher levels of glucose in utero develop hyperinsulinemia, than reduced surfactant production, weak stabilization of alveoli during emporium and development of RDS [7]. Macrosomia defined as birth weight $\geq 4000 \mathrm{~g}$ (above 90th percentile for gestational age) may occur in $12 \%$ of the newborns in general population and $15-45 \%$ of the GDM newborns. Birth weight above $4500 \mathrm{~g}$ carries $6 \mathrm{x}$ greater risk for birth traumatism and 20x greater risk for plexus brachialis injuries [7]. Neonatal hypoglycemia is an expected metabolic disorder, a transient complication in $50 \%$ of macrosomia newborns and $5-15 \%$ of optimally controlled GDM [8]. Neonatal hyperbilirubinemia is associated complication of polycythemia as a result in immature system for bilirubin conjugation in newborns form GDM mothers. Hyperglycemia affects the organogenesis and leads to increased malformation risk in GDM. GDM women more often have history of early fetal loss and GDM can be the link between spontaneous abortions, PCOS and insulin resistance [9]. All forms of diabetes in pregnancy are related to increased risk for stillbirth therefore adequate prenatal care, multidisciplinary approach, ultrasound monitoring, nonstress test and careful assessment for delivery time is needed [10].

\section{Material and Methods}

Prospective longitudinal case control study was made at the University clinic for ob@gyn in Skopje in a 2-year interval. Pregnant women that had prenatal care at the outpatient department in the Clinic in that period were selected. From the ob@gyn specialist in primary, secondary and tertiary levels of care patients were scheduled for GDM screening with $75 \mathrm{~g}$ OGTT at the biochemical laboratory at the clinic. Pregnant women with gestational diabetes were selected as investigated group and patients with negative OGTT were in the Control Group (CG). They were with matching gestational age, party and maternal age. Inclusion criteria were: maternal age between 18 and 45, eligibility for follow up, first prenatal visit before 20 gestational week, GDM diagnosed by IADPSG criteria with 75g OGTT in the morning after night feast with venous blood drawn 0, 60 and 120 minutes after ingestion of $75 \mathrm{~g}$ of glucose dissolved in $200 \mathrm{ml}$ of water with reference values: 0 $<5,1,1$-h $<10,0,2$-h $<8,5 \mathrm{mmol} / \mathrm{L}$.

Exclusion Criteria: were pregestational diabetes, chronic hypertension, chronic inflammatory condition, stillbirth, fetal anomalies, noninfectious syndrome. By medical scale body weight and height was measured for all the pregnant women. Body Mass
Index-BMI was calculated with the formula = weight $(\mathrm{kg}) /$ height (m2). Monthly gestational weight gain, blood pressure and urine analyses for proteinuria was noted. Patients were delivered at the University ob@gyn clinic. By a pediatrician 1st and 5th minute Apgar score was estimated (respirations, heartbeat, muscle tonus, reflexes and skin color). Each criteria were calculated by 0,1 or 2 points according to the conditions that was observed. After delivery the umbilical cord was double clamped and blood sample was taken from the umbilical artery for arterial acid base status (Rapid point 405 , Siemens). From the newborn babies blood sample for glucose levels (glucose oxidase, Beckman Glucose Analyzer) and bilirubin levels (Total Bilirubin assay, ARCHITECT c Systems) was collected according to the pediatrician assessment.

\section{Perinatal Data}

Detail medical and clinical information on delivery outcome for all mothers and newborns were taken from maternal and neonatal medical records: way of delivery, complications during and after birth, admission of the newborn in ICU, neonatal outcome.

a) Composite Maternal Outcome Includes: GWG, gestational weight gain; hypertensive disorders of pregnancy: pregnancy induced hypertension, preeclampsia (blood pressure $>140 / 90$ mmHg with proteinuria $>0.3 \mathrm{~g} / 24 \mathrm{~h}$ or ++ on isolated sample); premature delivery $(<37$ gestational weeks); caesarean section and intrauterine fetal death.

b) Composite Neonatal Outcome Includes: neonatal weight/ length ; 1st and 5th minute Apgar score of the newborn; acidbase status of the newborn 5 minutes after birth; neonatal hyperbilirubinemia:>12 mg/dl; clinical and biochemical neonatal hypoglycemia: 2 or more neonatal glycemia below value of $2.6 \mathrm{mmol} / \mathrm{l}$; neonatal Respiratory Distress Syndrome (RDS): need of at least 4 hours respiratory support by supplemental oxygen), transitional tachypnea of the newborn. Study was approved by Ethical committee and all subjects have confirmed informative consent.

\section{Statistical analysis}

a) Data was analysed with statistical computer programme SPSS 23 for Windows.

b) numeric data was given with descriptive statistics (standard deviation, median and interquartile interval).

c) qualitative data was shown in absolute and relative values.

d) for comparison of analysed groups nondependent parametric and nonparametric tests were used. (Student t-test for independent samples, Chi-square тест, Fisher exact тест, Mann-Whitney тест).

e) for all analyses p value $<0,05$ was taken as statistically significant. 
f) Data on perinatal outcome was taken from the medical records on discharge form the clinic.

\section{Results}

One hundred pregnant women which had an OGTT in the biochemical laboratory at the University clinic for ob@gyn were included in the study and divided into 2 groups (Figure 1):

a) Gestational diabetes Melitus or investigated group, $n=50$ women

b) Control group with negative OGTT, $n=50$ women

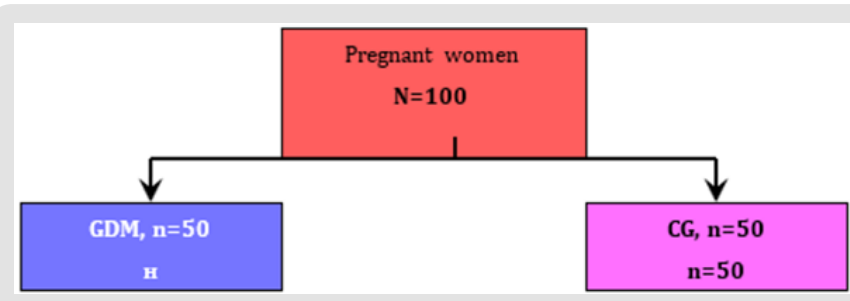

Figure 1: The pregnant women were treated with diet $(n=34,68 \%)$, insulin therapy $(n=14,28 \%)$ and 2 women had metformin $(n=2,4 \%)$.

\section{Body Mass Index (Bmi) In Gdm and Normoglycemic Women}

The body mass index had values between 18.7 and 48 in the GDM group and between 21 and 41 in the control group. Average value of BMI was $31.01 \pm 7.1$ in the GDM group and $26.85 \pm 4.3$ in the control group. The difference of 4.16 was statistically confirmed as significant for $\mathrm{p}=0.0006$, (Table 1 ).

Table 1: BMI in GDM and CG.

\begin{tabular}{|c|c|c|c|c|}
\hline \multirow{2}{*}{ Groups } & \multicolumn{3}{|c|}{ Descriptive Statistics (BMI) } & \multirow{2}{*}{ P Value } \\
\cline { 2 - 4 } & Mean \pm SD & Std err & Min - Max & \\
\hline GDM & $31.01 \pm 7.1$ & 0.998 & $18.7-48$ & $\begin{array}{c}t=3.55 \\
\mathrm{p}=0.0006 \text { sig }\end{array}$ \\
\hline CG & $26.85 \pm 4.3$ & 0.612 & $21-41$ & \\
\hline
\end{tabular}

Note: $\mathrm{t}$ (Student t-test)

\section{Gestational Weight (Gwg) In Gdm}

Pregnant women with GDM had insignificantly more gestational weight gain than the ones without GDM $(12.54 \pm 4.7$ vs $11.44 \pm$ $4.4 ; \mathrm{p}=0.23$, Table 2). Pregnant women with GDM more often than the control group gained between 10 and $14 \mathrm{~kg}-46 \%$ vs $36 \%$. Also, more often they gained more than $15 \mathrm{~kg}-36 \%$ vs $28 \%$. The difference of this distribution was not statistically confirmed as significant ( $\mathrm{p}=0.13$, Table 3 ).

Table 2: Gestational weight gain/GWG in GDM and control group.

\begin{tabular}{|c|c|c|c|c|}
\hline \multirow{2}{*}{ Groups } & \multicolumn{3}{|c|}{ Descriptive Statistics (GWG) } & \multirow{2}{*}{ P Value } \\
\cline { 2 - 4 } & Mean \pm SD & Std err & Min - Max & \\
\hline GDM & $12.54 \pm 4.7$ & 0.664 & $5-30$ & $\mathrm{t}=1.21$ \\
\hline CG & $11.44 \pm 4.4$ & 0.622 & $3-20$ & $\mathrm{p}=0.23 \mathrm{~ns}$ \\
\hline
\end{tabular}

Note: $\mathrm{t}$ (Student $\mathrm{t}$-test)
Table 3: Distribution of GWG in GDM and CG.

\begin{tabular}{|c|c|c|c|c|}
\hline \multirow{2}{*}{ GWG } & \multicolumn{3}{|c|}{ Groups } & \multirow{2}{*}{ P Value } \\
\cline { 2 - 4 } & $\mathbf{N}$ & $\begin{array}{c}\text { GDM } \\
\mathbf{n}(\%)\end{array}$ & $\begin{array}{c}\text { CG } \\
\mathbf{n}(\%)\end{array}$ & \\
\hline$<9 \mathrm{~kg}$ & 27 & $9(18)$ & $18(36)$ & \multirow{2}{*}{$\mathrm{X}^{2}=4.11$} \\
\hline $10-14 \mathrm{~kg}$ & 41 & $23(46)$ & $18(36)$ & $\mathrm{p}=0.13 \mathrm{~ns}$ \\
\hline$>15 \mathrm{~kg}$ & 32 & $18(36)$ & $14(28)$ & \\
\hline
\end{tabular}

Note: $\mathrm{p}$ (Chi-square test)

\section{Premature Delivery in Gdm}

Pregnant women with GDM significantly more often had premature delivery compared to normoglycemic women $(20 \%$ vs 4\%, $\mathrm{p}=0.014$ ), Table 4 .

Table 4: Distribution of GWG in GDM and CG.

\begin{tabular}{|c|c|c|c|c|}
\hline \multirow{2}{*}{$\begin{array}{c}\text { Premature } \\
\text { delivery }\end{array}$} & \multicolumn{3}{|c|}{ Groups } & \multirow{2}{*}{ P Value } \\
\cline { 2 - 4 } & N & $\begin{array}{c}\text { GDM } \\
\text { n (\%) }\end{array}$ & $\begin{array}{c}\text { CG } \\
\text { n (\%) }\end{array}$ & \\
\hline No & 88 & $40(80)$ & $48(96)$ & \multirow{2}{*}{$\mathrm{X}^{2}=6.06$} \\
\hline Yes & 12 & $10(20)$ & $2(4)$ & $\mathrm{p}=0.014$ sig \\
\hline
\end{tabular}

Note: $\mathrm{p}($ Chi-square test)

\section{Hypertensive Disorders of Pregnancy in Gdm}

In $26 \%$ of pregnant women with GDM vs $6 \%$ of the control group hypertensive disorders of pregnancy occurred. Our results showed GDM was significantly associated with hypertensive disorders of pregnancy $(\mathrm{p}=0.0064)$, Table 5 .

Table 5: Hypertensive disorders of pregnancy and GDM.

\begin{tabular}{|c|c|c|c|c|}
\hline \multirow{2}{*}{$\begin{array}{c}\text { Hypertensive } \\
\text { disorders of } \\
\text { pregnancy }\end{array}$} & N & $\begin{array}{c}|c| \\
\text { GDM } \\
\text { n (\%) }\end{array}$ & $\begin{array}{c}\text { Controls } \\
\text { n (\%) }\end{array}$ & P Value \\
\cline { 2 - 4 } & 84 & $37(74)$ & $47(94)$ & \multirow{2}{*}{$\mathrm{X}^{2}=7.44$} \\
\hline No & 16 & $13(26)$ & $3(6)$ & $\mathrm{p}=0.0064 \mathrm{sig}$ \\
\hline
\end{tabular}

Note: $\mathrm{p}$ (Chi-square test)

\section{Way of Delivery in Gdm}

Statistically significantly different was way of delivery in pregnant women with or without GDM ( $\mathrm{p}=0.045)$. Pregnant women with GDM were delivered more often with caesarean section- $64 \%$ vs $44 \%$, or delivery was less likely to be spontaneous- $36 \%$ vs $56 \%$ (Table 6).

Table 6: Hypertensive disorders of pregnancy and GDM.

\begin{tabular}{|c|c|c|c|c|}
\hline \multirow{2}{*}{$\begin{array}{c}\text { Way of } \\
\text { delivery }\end{array}$} & $\mathbf{3}$ & \multirow{2}{*}{ Proups } \\
\cline { 2 - 4 } & $\mathbf{N}$ & $\begin{array}{c}\text { GDM } \\
\mathbf{n}(\%)\end{array}$ & $\begin{array}{c}\text { Controls } \\
\mathbf{n}(\%)\end{array}$ & \\
\hline Spontaneous & 46 & $18(36)$ & $28(56)$ & \multirow{2}{*}{$\mathrm{X}^{2}=4.03$} \\
\hline $\begin{array}{c}\text { Caesarean } \\
\text { section }\end{array}$ & 54 & $32(64)$ & $22(44)$ & $\mathrm{p}=0.045 \mathrm{sig}$ \\
\hline
\end{tabular}

Note: $\mathrm{p}$ (Chi-square test) 


\section{Neonatal Birth Weight and Length in Gdm}

Minimal neonatal birth weight in GDM group was $1230 \mathrm{~g} v \mathrm{~s} 1800$ $\mathrm{g}$ in the control group. Maximal neonatal birth weight was $4470 \mathrm{~g}$ in GDM group and 4220g in the control group. Average neonatal birth weight was $3220.4 \pm 784.9 \mathrm{~h}$ in GDM vs $3290.6 \pm 450.9 \mathrm{~g}$ in the control group (Table 7). There was not a significant difference in the birth weight $(p=0.58)$ and in birth length of newborn babies in form both groups $(p=0.21)$. Most probable reason for this outcome is the larger percent of premature deliveries in GDM and smaller birth weight and length of these newborns. Average birth length of newborns in GDM group was $49.58 \pm 3.3 \mathrm{~cm}$, and in groups of mothers with negative OGTT was $50.26 \pm 1.9 \mathrm{~cm}$, (Table 8).

Table 7: Average birth weight in newborns from GDM vs control group

\begin{tabular}{|c|c|c|c|c|}
\hline \multirow{2}{*}{ Groups } & \multicolumn{3}{|c|}{ Descriptive Statistics (Birth weight/ } & \multirow{2}{*}{ P Value } \\
\cline { 2 - 4 } & Mean \pm SD & Std Err & Min - Max & \\
\hline GDM & $3220.4 \pm 784.9$ & 110.99 & $1230-4470$ & \multirow{2}{t}{$=0.55$} \\
& CG $=0.58 \mathrm{~ns}$ \\
\hline
\end{tabular}

Note: $t$ (Student t-test)

Table 8: Birth length in newborns from GDM vs CG.

\begin{tabular}{|c|c|c|c|c|}
\hline \multirow{2}{*}{ Groups } & \multicolumn{3}{|c|}{ Descriptive Statistics (Birth length cm) } & \multirow{2}{*}{ P Value } \\
\cline { 2 - 4 } & Mean \pm SD & Std Err & Min - Max & \\
\hline GDM & $49.58 \pm 3.3$ & 0.474 & $38-55$ & \multirow{2}{*}{$\mathrm{t}=1.25$} \\
\hline CG & $50.26 \pm 1.9$ & 1.861 & $44-54$ & $\mathrm{p}=0.21 \mathrm{~ns}$ \\
\hline
\end{tabular}

Note: $\mathrm{t}$ (Student t-test)

\section{Apgar Score in Newborns from Gdm Vs Normoglycemic Women}

Table 9: $1^{\text {st }}$ minute Apgar score in GDM and CG.

\begin{tabular}{|c|c|c|c|}
\hline \multirow{2}{*}{\begin{tabular}{c} 
st $\begin{array}{c}\text { min Apgar } \\
\text { score }\end{array}$ \\
\cline { 2 - 4 }
\end{tabular}} & $\mathbf{3}$ & \multicolumn{3}{|c|}{ Groups } \\
\hline 4 & 1 & GDM n (\%) & CG n (\%) \\
\hline 5 & 2 & $2(2)$ & 0 \\
\hline 6 & 4 & $3(6)$ & 0 \\
\hline 7 & 15 & $11(22)$ & $4(2)$ \\
\hline 8 & 70 & $30(60)$ & $40(80)$ \\
\hline 9 & 8 & $3(6)$ & $5(10)$ \\
\hline
\end{tabular}

In table distribution of pregnant women with and without GDM in terms of Apgar score 1 minute after birth is shown, (Table 9). Average 1st minute Apgar score in GDM was $7.52 \pm 0.9$, and was significantly lower than control group, $7.98 \pm 1.2$, ( $\mathrm{p}=0.04)$, (Table 10). We compared both groups in terms of value of 1 st minute Apgar score smaller and bigger than 7. In the GDM group $12 \%$ of the newborns had 1st minute Apgar score smaller than 7 and in the control group than percent was $2 \%$. That difference wasn't statistically different $(\mathrm{p}=0.12)$, (Table 11). In the Table 12 distribution of pregnant women with or without GDM about $5^{\text {th }}$ minute Apgar score is shown. AS in the 5 th minute had lower average value in GDM but no statistical significance (8.54 \pm 0.9 vs $8.86 \pm 1.3 ; p=0.16$ ), (Table 13). AS lower than 7 in the 5 th minute had 2 newborn babies in the GDM group and none in the control group (Table 14).

Table 10: Average $1^{\text {st }}$ minute Apgar score in GDM and CG.

\begin{tabular}{|c|c|c|c|c|}
\hline \multirow{2}{*}{ Groups } & \multicolumn{3}{|c|}{ Descriptive Statistics (AS $1^{\text {st }}$ Minute) } & \multirow{2}{*}{ P Value } \\
\hline & mean $\pm S D$ & Median & IQR & \\
\hline GDM & $7.52 \pm 1.0$ & 8 & $7-8$ & \multirow{2}{*}{$\begin{array}{c}t=1.43 \\
p=0.04 \mathrm{sig}\end{array}$} \\
\hline CG & $7.98 \pm 1.2$ & 8 & $7-8$ & \\
\hline
\end{tabular}

Note: $\mathrm{t}$ (Student t-test)

Table 11: $1^{\text {st }}$ minute Apgar score $<7$ in GDM and control group.

\begin{tabular}{|c|c|c|c|c|}
\hline \multirow{2}{*}{\begin{tabular}{c}
$\mathbf{1}^{\text {st }}$ minute \\
\cline { 2 - 4 }
\end{tabular}} & $\mathbf{3}$ & \multirow{2}{*}{ Proups } \\
\cline { 2 - 3 } & $\mathbf{N}$ & $\begin{array}{c}\text { GDM } \\
\mathbf{n}(\%)\end{array}$ & $\begin{array}{c}\text { CG } \\
\mathbf{n}(\%)\end{array}$ & \\
\hline$>7$ & 8 & $6(12)$ & $1(2)$ & \multirow{2}{*}{$\begin{array}{c}\mathrm{t}=1.25 \\
\mathrm{p}=0.21 \mathrm{~ns}\end{array}$} \\
\hline
\end{tabular}

Note: Yates Chi-square test $=2.46 \mathrm{p}=0.117$

Table 12: $5^{\text {th }}$ minute Apgar score in GDM and CG.

\begin{tabular}{|c|c|c|c|}
\hline \multirow{2}{*}{$\mathbf{5}^{\text {th }}$ minute AS } & \multicolumn{3}{|c|}{ Groups } \\
\cline { 2 - 4 } & $\mathbf{N}$ & GDM $\mathbf{n}(\%)$ & CG n (\%) \\
\hline 5 & 1 & $1(2)$ & 0 \\
\hline 6 & 1 & $1(2)$ & 0 \\
\hline 7 & 5 & $3(6)$ & $2(4)$ \\
\hline 8 & 18 & $12(24)$ & $6(12)$ \\
\hline 9 & 70 & $31(62)$ & $39(78)$ \\
\hline 10 & 5 & $2(4)$ & $3(6)$ \\
\hline
\end{tabular}

Table 13: Average value of $5^{\text {th }}$ minute AS in GDM and control group.

\begin{tabular}{|c|c|c|c|c|}
\hline \multirow{2}{*}{ Groups } & \multicolumn{3}{|c|}{ DescriptiveStatistics (5 $5^{\text {th }}$ min) } & \multirow{2}{*}{ P Value } \\
\cline { 2 - 4 } & Mean \pm SD & Median & IQR & \\
\hline GDM & $8.54 \pm 0.9$ & 9 & $8-10$ & \multirow{2}{*}{$\begin{array}{c}\mathrm{t}=0.78 \\
\mathrm{p}=0.16 \mathrm{~ns}\end{array}$} \\
\hline CG & $8.86 \pm 1.3$ & 9 & $9-10$ & $\mathrm{n}$ \\
\hline
\end{tabular}

Note: $\mathrm{t}$ (Student t-test)

Table 14: $5^{\text {th }}$ minute AS in GDM and CG.

\begin{tabular}{|c|c|c|c|c|}
\hline \multirow{2}{*}{$5^{\text {th }} \mathbf{m i n}$ AS } & \multicolumn{3}{|c|}{ Groups } & \multirow{2}{*}{ P Value } \\
\cline { 2 - 4 } & $\mathbf{N}$ & $\begin{array}{c}\text { ГДM } \\
\mathbf{n}(\%)\end{array}$ & $\begin{array}{c}\mathbf{K} \mathbf{1 \%} \\
\mathbf{n}(\%)\end{array}$ & \\
\hline$<7$ & 2 & $2(4)$ & 0 & \multirow{2}{*}{$\mathrm{p}=0.48 \mathrm{~ns}$} \\
\hline$>7$ & 98 & $48(96)$ & $50(100)$ & \\
\hline
\end{tabular}

Note: $\mathrm{t}$ (Student $\mathrm{t}$-test)

\section{Neonatal Respiratory Distress Syndrome in Gdm Vs Control Group}

In our research neonatal respiratory distress syndrome was significantly associated with gestational diabetes mellitus 
$(\mathrm{p}=0.005)$. Distribution in Table 15 is presenting $30 \%$ of the newborns in GDM and 8\% in the control group with RDS, Table 15.

Table 15: Neonatal respiratory distress syndrome in GDM.

\begin{tabular}{|c|c|c|c|c|}
\hline \multirow[b]{2}{*}{ RDS } & \multicolumn{3}{|c|}{ Groups } & \multirow[b]{2}{*}{$P$ Value } \\
\hline & $\mathbf{N}$ & $\begin{array}{l}\text { GDM } \\
\text { n (\%) }\end{array}$ & $\begin{array}{c}\text { CG } \\
\text { n (\%) }\end{array}$ & \\
\hline No & 81 & $35(70)$ & $46(92)$ & \multirow{2}{*}{$\begin{array}{c}X^{2}=7.86 \\
p=0.005 \mathrm{sig}\end{array}$} \\
\hline Yes & 19 & $15(30)$ & $4(8)$ & \\
\hline
\end{tabular}

Note: Yates Chi-square test $=0.51 \mathrm{p}=0.476$

\section{Neonatal Hypoglycemia in Gdm Vs Control Group}

In the GDM group neonatal hypoglycemia was registered in $26 \%$ of the newborns and significantly more rare in control group, $8 \%$ of the newborns, (Table 16). Neonatal hypoglycemia was significantly associated with GDM ( $\mathrm{p}=0.016)$.

Table 16: Neonatal hypoglycemia in GDM.

\begin{tabular}{|c|c|c|c|c|}
\hline \multirow[b]{2}{*}{ Hypoglycemia } & \multicolumn{3}{|c|}{ Groups } & \multirow{2}{*}{ P Value } \\
\hline & $\mathbf{N}$ & $\begin{array}{c}\text { GDM } \\
\text { n (\%) }\end{array}$ & $\begin{array}{c}\text { CG } \\
\text { n (\%) }\end{array}$ & \\
\hline No & 83 & $37(74)$ & $46(92)$ & \multirow{2}{*}{$\begin{array}{c}X^{2}=5.74 \\
p=0.016 \text { sig }\end{array}$} \\
\hline Yes & 17 & $13(26)$ & $4(8)$ & \\
\hline
\end{tabular}

Note: $\mathrm{p}($ Chi-square test)

\section{Acid Base Status in Newborns from Gdm Mothers}

There was a significant difference in the acid base status of the newborns between women with and without GDM ( $\mathrm{p}=0.027)$. In $12 \%$ of the newborns in GDM group 5 minutes after birth umbilical cord ph $<7.25$ was measured. In the control group there was no such case, (Table 17).

Table 17: Acid-base status in newborn - ph<7.25 in GDM and CG.

\begin{tabular}{|c|c|c|c|c|}
\hline \multirow{2}{*}{$\mathbf{p h}<7.25$} & \multicolumn{3}{|c|}{ Groups } & \multirow{2}{*}{ P Value } \\
\cline { 2 - 4 } & $\mathbf{N}$ & $\begin{array}{c}\text { GDM } \\
\mathbf{n}(\%)\end{array}$ & $\begin{array}{c}\text { CG } \\
\mathbf{n}(\%)\end{array}$ & \\
\hline No & 94 & $44(88)$ & $50(100)$ & \multirow{2}{*}{$\mathrm{p}=0.027 \mathrm{sig}$} \\
\hline Yes & 6 & $6(12)$ & 0 & \\
\hline
\end{tabular}

Note: $\mathrm{p}$ (fisher)

\section{Neonatal Hyperbilirubinemia in Gdm}

This neonatal outcome was more often in GDM babies (28\% vs $14 \%$ ) but with no statistical significance ( $p=0.086$, Table 18).

Table 18: Neonatal hyperbilirubinemia and GDM.

\begin{tabular}{|c|c|c|c|c|}
\hline \multirow{2}{*}{$\begin{array}{c}\text { Neonatal } \\
\text { hyperbilirubinemia }\end{array}$} & \multicolumn{3}{|c|}{ Groups } & \multirow{2}{*}{ P Value } \\
\cline { 2 - 4 } & $\mathbf{N}$ & $\begin{array}{c}\text { GDM } \\
\text { n (\%) }\end{array}$ & $\begin{array}{c}\text { CG } \\
\text { n (\%) }\end{array}$ & \\
\hline No & 79 & $36(72)$ & $43(86)$ & \multirow{2}{*}{$\begin{array}{c}\mathrm{X}^{2}=2.95 \\
\mathrm{p}=0.086 \mathrm{~ns}\end{array}$} \\
\hline Yes & 21 & $14(28)$ & $7(14)$ & \multicolumn{2}{|c|}{} \\
\hline
\end{tabular}

Note: $\mathrm{p}$ (Chi-square test)

\section{Admission of The Newborns from Gdm Mothers in Intensive Care Unit}

In the GDM group $12 \%$ of the newborns were admitted in the intensive care unit whereas in the control group there was no such case. This neonatal outcome was statistically significant for $\mathrm{p}=0.027$, (Table 19).

Table 19: Admission of the newborns form GDM in ICU.

\begin{tabular}{|c|c|c|c|c|}
\hline \multirow{2}{*}{ ICU } & \multicolumn{3}{|c|}{ Groups } & \multirow{2}{*}{ P Value } \\
\cline { 2 - 4 } & N & $\begin{array}{c}\text { GDM } \\
\text { n (\%) }\end{array}$ & $\begin{array}{c}\text { CG } \\
\text { n (\%) }\end{array}$ & \\
\hline No & 94 & $44(88)$ & $50(100)$ & \multirow{2}{*}{$\mathrm{X}^{2}=2.95$} \\
\cline { 1 - 3 }$=0.086 \mathrm{~ns}$
\end{tabular}

Note: $\mathrm{p}$ (Chi-square test)

\section{Neonatal Outcome in Gdm And Normoglycemic Women}

There was a one case of neonatal death from complications related to prematurity, (Table 20).

Table 20: Neonatal death in GDM and control group.

\begin{tabular}{|c|c|c|c|}
\hline \multirow{2}{*}{ Neonatal death } & \multicolumn{3}{|c|}{ Groups } \\
\cline { 2 - 4 } & N & GDM n (\%) & CG n (\%) \\
\hline No & 99 & $49(98)$ & $50(100)$ \\
\hline Yes & 1 & $1(2)$ & 0 \\
\hline
\end{tabular}

Note: $\mathrm{p}$ (fisher)

\section{Discussion}

GDM has a growing prevalence worldwide as the prevalence of obesity is growing. The unfavorable perinatal outcome associated with GDM results from the metabolic milieu projected to the fetus through the placenta [1].

Women with GDM in our study and according to the studies from Catalano и Chu more often were overweight or obese $[11,12]$. Average BMI was $31.01 \pm 7.1$ in GDM and $26.85 \pm 4.3$ in the control group $(\mathrm{p}=0.0006)$. Although gestational weight gain was not statistically significant in our study, we think that is an important clinical parameter in followment of these patients. Pregnant women with positive OGTT test were referred to endocrinologist for glycemic monitoring and treatment: most of them had diet ( $n=34,68 \%)$, some had insulin ( $n=14,28 \%)$ and only 2 had metformin $(n=2,4 \%)$. Prenatal care in GDM women was according to the clinical protocol. Deliveries were spontaneous or C section according to the case. There were no cases of vacuum or forceps deliveries and no birth traumatism. GDM is associated to hypertensive disorders of pregnancy. In our study $26 \%$ vs $6 \%$ in the control group, $\mathrm{p}=0.0064$ which confirmed findings of Ross et al. [13]. In our study GDM women significantly more had premature delivery $-20 \%$ vs $4 \%$, p=0.014, similar as findings of Kock et al. [6].

There was a one case of cardiopathy in GDM group and one case of neonatal death due to prematurity issues. GDM is associated also 
with elective or urgent cesarean section [4]. Our results showed $64 \%$ incidence in GDM group vs $44 \%$ in the control group, $\mathrm{p}=0.045$. Due to prematurity rate in GDM average birth weight in GDM was $3220.4 \mathrm{~g} \pm 784(1230-4470 \mathrm{~g})$ and in the control group $3290.6 \mathrm{~g} \pm$ 450 (1800-4220g). According to our results average 1st minute Apgar score in GDM was $7.52 \pm 0.9$, significantly lower than control group- $7.98 \pm 1.2$ ( $\mathrm{p}=0.04$ ). Jones et al found association between GDM and neonatal respiratory distress, similar as our study [14]. Neonatal hypoglycemia according to our results was significantly associated to GDM (26\% incidence vs $8 \%$ in the control group, $\mathrm{p}=0.016$ ). Screening for hypoglycemia in all newborns form diabetic mothers should be done in the early neonatal period because of the risk for convulsions and poor neurologic [8]. Our findings showed significant difference in acid base status between 2 groups of newborns, none of the control group had umbilical artery ph $<7.25$ vs $12 \%$ of GDM group ( $\mathrm{p}=0.027)$ similar as study of Aalipur et al. [15].

Paunikare et al. [16] in a study of 900 women, out of which 30 had GDM found that the incidence of neonatal hyperbilirubinemia in GDM mothers was $13 \%$. Our results were $28 \%$ in GDM vs $14 \%$ in the control group. NICU admission is more often in GDM newborns than in general population. Hakeem et al. [4] found incidence of 4.9\%, 5.1\% in Da Silva et al. [17], 6.7\% in Palatnik et al. [18]. Compared to these results we have higher incidence, $12 \%$ $(p=0.027)$ which is because of the higher rate of premature labour in our case, $\mathrm{p}=0.027$.

\section{Conclusion}

There was a significant difference in BMI, hypertensive disorders of pregnancy, preterm labour and cesarean section deliveries between women with GDM vs normoglycemic women. Neonatal respiratory distress, neonatal hypoglycemia, umbilical cord ph $<7.25$, lower $1^{\text {st }}$ minute Apgar score and NICU admission significantly was associated with mothers with GDM. Therefore, adequate prenatal care and treatment of GDM can achieve better maternal and neonatal outcome.

\section{References}

1. Metzger BE, Lowe LP, Dyer AR, Trimble ER, Chaovarindr U, et al. (2008) The HAPO Study Cooperative Research Group. Hyperglycemia and Adverse Pregnancy Outcomes. N Eng J Med 358(19): 1991-2002.

2. Boyd E Metzger (2010) International Association of Diabetes and Pregnancy Study Groups. Recommendations on the Diagnosis and Classification of Hyperglycemia in Pregnancy. Diabetes Care 33(3): 676682.
3. Risto Kaaja, Tapani Rönnemaa (2008) Gestational Diabetes: Pathogenesis and Consequences to Mother and Offspring. Rev Diabet Stud 5(4): 194-202.

4. Malak M Al Hakeem (2006) Pregnancy Outcome of Gestational Diabetic Mothers: Experience in A Tertiary Center. J Family Community Med 13(2): 55-59.

5. Beigelman A, Wiznitzer A, Shoham Vardi I, Vardi H, Holtcberg G, et al. (2000) Premature delivery in diabetes: etiology and risk factors. Harefuah 138(11): 919-923.

6. Köck K, Köck F, Klein K, Bancher Todesca D, Helmer H (2010) Diabetes mellitus and the risk of preterm birth with regard to the risk of spontaneous preterm birth. J Matern Fetal Neonatal Med 23(9): 10041008.

7. KC K, Shakya S, Zhang H (2015) Gestational Diabetes Mellitus and Macrosomia: A Literature Review. Ann Nutr Metab 66(suppl 2): 14-20.

8. A Stanescu, SM Stoicescu (2014) Neonatal hypoglycemia screening in newborns from diabetic mothers - Arguments and controversies. J Med Life 7(Spec Iss 3): 51-52.

9. Correa A, Gilboa SM, Besser L M, Botto L D, Moore C A, et al. (2008) Diabetes mellitus and birth defects". American J Obstetrics Gynecology 199(3): 237.

10. Girz BA, Divon MY, Merkatz IR (1992) Sudden fetal death in women with well-controlled, intensively monitored gestational diabetes. J Perinatol 12(3): 229-233.

11. Catalano PM, Ehrenberg HM (2006) The short- and long-term implications of maternal obesity on the mother and her offspring. BJOG 113(10): 1126-1133.

12. Chu SY, Callaghan WM, Kim SY, Schmid CH, Lau J, et al. (2007) Maternal obesity and risk of gestational diabetes mellitus. Diabetes Care 30(8): 2070-2076

13. Ross G (2006) Gestational diabetes. Australian family physician 35(6): 392-396.

14. Jones C W (2001) Gestational diabetes and its impact on the neonate. Neonatal network 20(6): 17-23.

15. Aalipour S, Hantoushzadeh S, Shariat M, Sahraian S, Sheikh M, et al. (2018) Umbilical Cord Blood Acidosis in Term Pregnancies with Gestational Diabetes Mellitus and Its Relations to Maternal Factors and Neonatal Outcomes, IRC Med J.

16. Vaishali M Paunikare (2015) Neonatal Complications of Gestational Diabetes Mellitus. Scholars J of Applied Medical Sciences 3(8D): 2985 2988.

17. Amanda L daSilva, Augusto $\mathrm{R}$ doAmaral, Daniela S deOliveira, LisianeMartins, Mariana R, et al. (2017) Neonatal outcomes according to different therapies for gestational diabetes mellitus. Jornal de Pediatria 93(1): 87-93.

18. Anna Palatnik, Lisa Mele, Mark B Landon, Uma M Reddy, Susan M Ramin, et al. (2015) Timing of treatment initiation for mild gestational diabetes and perinatal outcomes. Am J Obstet Gynecol 213(4). 
ISSN: 2574-1241

DOI: $10.26717 /$ BJSTR.2020.26.004338

Slagjana Simeonova Krstevska. Biomed J Sci \& Tech Res

(c) This work is licensed under Creative

Submission Link: https://biomedres.us/submit-manuscript.php

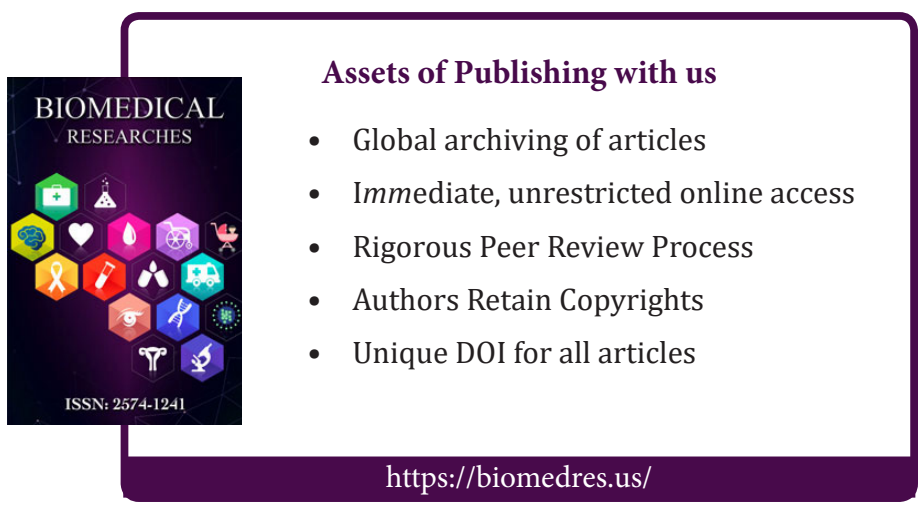

